\title{
MAKNA SIMBOLIS TRADISI MAPPAOLI BANUA pada masyarakat banua kaiyang mosso PROUINSI SULAWESI BARAT
}

\author{
SIMBOLICAL MEANING OF MAPPAOLI BANUATRADITION \\ IN BANUA KAIYANG MOSSO SOCIETY OF WEST SULAWESI
}

\author{
Raodah \\ Balai Pelestarian Nilai Budaya Makassar \\ Jalan Sultan Alauddin Km7 Makassar, 90221 \\ e-mail: raodahtul.janna@yahoo.com
}

\begin{abstract}
Abstrak
Mappaoli banua merupakan tradisi ritual pada masyarakat Banua Kaiyang Mosso di Kabupaten Polman, Provinsi Sulawesi Barat. Mappaoli banua bertujuan untuk mengobati dan menyucikan kampung, agar terhindar dari bencana alam dan wabah penyakit. Sampai sekarang tradisi ritual itu tetap bertahan dan menjadi agenda tahunan masyarakat Banua Kaiyang Mosso. Penelitian ini difokuskan untuk mengetahui dan mendiskripsikan prosesi pelaksanaan tradisi ritual mappaoli bапиа dan makna simbolis yang terkandung dalam tradisi ritual tersebut. Tradisi ritual mappaoli banua, mencerminkan karakter dan jati diri masyarakat Banua Kaiyang Mosso sehingga perlu dikaji dalam upaya melestarikan budaya lokal, sebagai bagian dari kekayaan budaya bangsa. Penelitian ini menggunakan metode kualitatif dengan pendekatan deskriptif. Teknik pengumpulan data melalui pengamatan, wawancara dan dokumentasi. Dari hasil penelitian diketahui bahwa, pelaksanaan tradisi ritual mappaoli banua terdiri atas beberapa tahap, yaitu: tahap persiapan, mapparawung sossorang (penurunan benda pusaka), mamminnai tedzong (pengolesan minyak pada kerbau), pangngereang tedzong (penyembelihan kerbau), massamaya (ziarah ke makam leluhur), dan mattanang uwae (memasang air untuk pengobatan). Setiap tahapan dalam ritual tersebut melambangkan simbol yang mengandung makna. Simbol mapparawung sossorang bermakna penghormatan kepada benda pusaka peninggalan leluhur, simbol mamminnai tedzong bermakna pembersihan pada hewan persembahan, simbol pangngereang tedzong bermakna hewan persembahan yang tertinggi kepada leluhur, simbol massamaya dimaknai sebagai wujud cinta dan bakti kepada leluhur dan ajang silaturrahmi masyarakat Banua Kaiyang Mosso. Simbol mattanang uwae bermakna sebagai pengobatan, keselamatan dan keberkahan manusia dan alam negeri Banua Kaiyang Mosso.
\end{abstract}

Kata kunci: ritual mappaoli banua, Banua Kaiyang Mosso.

\section{Abstract}

Mappaoli Banua is a ritual tradition in the community of Banua Kaiyang Mosso in Polman regency, West Sulawesi. Mappaoli Banua aims to treat and purify the village, in order to avoid natural disasters and disease outbreaks. Until now this ritual traditions survive and become an annual event of Banua Kaiyang Mosso community. This research is focused to identify and describe the ritual procession implementation of Mappaoli Banua tradition and the symbolic meaning contained in the ritual tradition. Mappaoli Banua ritual tradition reflects the character and identity of the Kaiyang Mosso people that need to be examined in an effort to preserve local culture, as part of the cultural wealth of the nation. This study used a qualitative method with descriptive approach. The technique of collecting data were through observation, interviews and documentation. The results revealed that the implementation of the tradition of ritual Mappaoli Banua consists of several stages: preparation, mapparawung sossorang (decrease heirlooms), mamminnaitedzong, (anointing on buffalo), pangngereang tedzong (slaughtering buffalo), 
massamaya (pilgrimage to ancestral graves) and mattanang uwae (install water treatment). Each stage in the ritual symbolizes the meaning implies. Symbol of mapparawung sossorang is meaningful homage to the ancestral heirlooms, symbols of tedzongmamminnai means cleaning animal offerings, tedzong pangngereang is a symbol of the highest animal sacrifice to the ancestors, massamaya symbols as a manifestation of love and devotion to the ancestors and the public arena of Banua Kaiyang Mosso. Mattanang Uwae symbol for the treatment, safety and human and natural land blessing of Banua Kaiyang Mosso.

Keywords: mappaoli banua rituals, Banua Kaiyang Mosso.

\section{A. PENDAHULUAN}

Ritual adalah seperangkat tindakan yang selalu melibatkan agama yang dimantapkan melalui tradisi. Ritual secara simbolik menggambarkan upaya manusia menjalin komunikasi dengan kekuatan transenden, apakah itu bersifat roh nenek moyang, makhluk halus, dewa-dewa, Tuhan ataupun daya magis lainnya. Suatu ritus dan upacara religi biasanya terdiri atas suatu kombinasi yang merangkaikan satu, dua, atau beberapa tindakan seperti: berdoa, bersujud, bersaji, berkorban, makan bersama, menari dan menyanyi, berprosesi, berseni drama, berpuasa, bertapa, dan bersemedi. Dengan demikian ritus keagamaan merupakan kinerja peribadahan yang terbentuk melalui ekspresi simbolik yang terbentuk melalui bahasa gerak dan pikir religius, yang kemudian menjadi keajaiban permanen (sakral) yang dijalankan secara terus menerus Koetnjaraningrat (1987: 81).

Mappaoli banua adalah salah satu tradisi ritual masyarakat Banua Kaiyang Mosso yang masih bertahan sampai sekarang. Mappaoli banua artinya mengobati negeri/ kampung, agar masyarakat terhindar dari bencana alam dan wabah penyakit, merupakan tradisi kuno peninggalan nenek moyang masyarakat Banua Kaiyang Mosso dan Arajang Balanipa. Suatu unsur kebudayaan akan tetap bertahan apabila masih memiliki fungsi atau peran dalam kehidupan masyarakatnya, sebaliknya unsur itu akan punah apabila budaya tersebut tidak berfungsi lagi. Demikian pula pada sebuah tradisi yang di dalamnya selalu terdapat ritual-ritual, yang merupakan unsur kebudayaan, tentu tidak akan bertahan apabila masyarakat pendukungnya tidak merasakan manfaatnya lagi. Akan tetapi sebaliknya akan bertahan apabila tradisi tersebut sudah menjadi bagian dari kehidupan masyarakat pendukungnya dan dirasakan memberi manfaat baik untuk keselamatan, harmonisasi dalam kehidupan bermasyarakat.

Tradisi sebagai salah satu bentuk kebudayaan mengandung sejumlah nilai yang berfungsi mengukuhkan pandangan masyarakat dan memberi arah dalam pergaulan yang diinginkan oleh norma dalam masyarakat (Udu, 2012: 1). Hal ini erat hubungannya dengan tradisi sebagai wadah penyimpanan norma sosial kemasyarakatan. Tradisi bertahan dalam jangka waktu tertentu dan mungkin lenyap jika benda material dibuang atau gagasan dilupakan. Tradisi akan muncul kembali setelah lama terpendam akibat terjadinya perubahan dan pergeseran sikap aktif terhadap masa lalu. Sebagian masyarakat dapat diikutsertakan pada tradisi tertentu yang kemudian akan memengaruhi masyarakat secara keseluruhan (Saifullah, 2007).

Bagi masyarakat Banua Kaiyang Mosso, melaksanakan ritual mappaoli banua sudah menjadi kesepakatan sejak dahulu, dan telah mengikat masyarakat pendukungnya untuk terus melaksanakannya. Masyarakat Banua Kaiyang Mosso rela untuk berkorban materi dan tenaga demi terlaksananya tradisi tersebut setiap tahunnya. Perayaan mappaoli banua dipercaya dapat membawa keberkahan, keselamatan dan 
ketentraman bagi negeri Banua Kaiyang Mosso, yang berdampak pada berbagai aspek kehidupan masyarakat, mulai dari aspek sosial, ekonomi, religi, budaya dan lain sebagainya. Realitas inilah, sehingga dianggap perlu dilakukan pengkajian tentang tradisi ritual mappaoli banua pada masyarakat Banua Kaiyang Mosso, dalam upaya melestarikan budaya lokal sebagai bagian dari khazanah budaya Nusantara. Adapun yang menjadi fokus dalam penelitian ini adalah bagaimana prosesi pelaksanaan ritual mappaoli banua dan apa makna simbol dari setiap tahapan dalam ritual mappaoli banua. Tujuan penelitian ini untuk mendiskripsikan prosesi pelaksanaan ritual mappaoli banua dan untuk mengetahui makna simbol-simbol dalam setiap tahapan ritual.

Dalam ritual mappaoli banua mengandung makna simbolik, yang bertujuan untuk disampaikan kepada masyarakat pendukungnya, agar dapat dimengerti dan dipahami sebagai pedoman dan panutan dalam menjalani kehidupan sehari-hari. Kekuatan simbol mampu menggiring orang yang memercayai, mengakui, melestarikan atau mengubah persepsi hingga tingkah laku orang, dalam bersentuhan dengan realitas. Daya magis simbol tidak hanya terletak pada kemampuannya mempersentasikan kenyataan, tetapi realitas juga dipersentasikan lewat penggunaan logika simbol.

Ciri khas simbol menurut Turner (dalam Endahwati, dkk. 2012: 157-170) yaitu: (a) multivokal, artinya simbol memiliki banyak arti menunjuk pada banyak hal, pribadi, dan fenomena, (b) polarisasi simbol, karena simbol memiliki banyak arti, sering ada arti simbol yang bertentangan, (c) unifikasi artinya memiliki arti terpisah.

Pemaknaan simbol-simbol sebagai pemaknaan pesan adalah suatu keharusan bagi sekelompok masyarakat terhadap aktivitas religi dan sistem kepercayaan yang dianutnya. Dalam prosesnya setiap tradisi selalu terjadi pemaknaan simbol simbol tertentu terhadap tahapan serta prosesi pelaksanaan ritual tradisi tersebut. Pemaknaan sendiri erat kaitannya dengan apa yang dinamakan persepsi. Persepsi adalah proses memberikan makna pada sensasi (sensasi merupakan proses menangkap stimulasi melalui indera). Dengan kata lain, persepsi mengubah sensasi menjadi informasi. Persepsi merupakan pengalaman tentang objek, peristiwa, atau hubungan-hubungan yang diperoleh dengan menyimpulkan informasi dan menafsirkan pesan (Desiderado, dalam Jumiaty 2013: 13).

Berkaitan dengan penelitian tradisi ritual mappaoli banua pada masyarakat Mandar, ada beberapa hasil penelitian terdahulu yang berkaitan dengan tradisi ritual orang Mandar telah dilakukan di antaranya penelitian Hafid (2010:57) tentang upacara baca-baca neneqta Adam di Lambanan Kabupaten Polman. Hasil penelitian tersebut mengungkapkan bahwa dalam pelaksanaan upacara adat baca-baca neneqta Adam banyak mengandung makna simbolik dalam proses pelaksanaannya, maupun sesajen yang ditampilkan. Dengan demikian makna simbolik tersebut dapat dijadikan sebagai filosofi dan pedoman dalam kehidupan pribadi maupun bermasyarakat. Masyarakat di Lambanan begitu mengsakralkan upacara neneqta Adam, sehingga masyarakat pendukungnya rela berkorban materi dan tenaga untuk pelaksanaan upacara tersebut, dengan harapan akan mendapat keselamatan dan ketenteraman jiwa. Demikian pula penelitian yang dilakukan oleh Ansaar (2010:65) tentang upacara massossor manurung yaitu pencucian benda pusaka Kerajaan Mamuju. Penyelenggaraan upacara massossor manurung diwarnai oleh sikap, tindakan dan ucapan-ucapan simbolik yang memiliki makna budaya sebagai cerminan adanya sistem nilai-nilai luhur yang sejak lama telah tumbuh dan berkembang dalam masyarakat pendukungnya. Dalam tulisan (Ismail,2014:277-287) ritual nelayan Mandar, mengungkapkan simbol-simbol 
dalam kuliwa (doa keselamatan) dari berbagai sesajen yang disajikan. Simbol tersebut mengandung makna doa keselamatan yang tidak terlafazkan.

\section{B. METODE PENELITIAN}

Penelitian ini menggunakan metode kualitatif, dengan maksud untuk mendiskripsikan data yang diperoleh dari orang-orang yang terlibat dalam tradisi mappaoli banua. Penelitian kualitatif ini didasarkan pada pendekatan karakteristik penelitian antara lain: pertama pada penelitian kualitatif, pengumpulan datanya dilakukan dalam latar yang wajar atau alamiah (natural setting), bukan dalam kondisi yang terkendali atau laboratories. Kedua, metode yang dilakukan dalam penelitian ini didasarkan pada fenomena sosial, penelitian kualitatif yaitu penelitian yang menghasilkan data diskriptif berupa kata-kata tertulis atau lisan dari orangorang dan pelaku yang dapat diamati. Ketiga, pendekatan ini diarahkan pada individu yang utuh (Moeleong, 2001: 4).

Lokasi penelitian di Desa Mosso, Kecamatan Balanipa, Kabupaten Polman Provinsi Sulawesi Barat. Pemilihan lokasi tersebut didasarkan atas pertimbangan bahwa tradisi mappaoli banua sejak dahulu hanya dilakukan oleh masyarakat Banua Kaiyang Mosso sebagai masyarakat pendukung tradisi tersebut. Data yang dikumpulkan dalam penelitian ini berasal dari dua sumber yaitu data primer dan data sekunder. Data primer adalah data yang diperoleh melalui pengamatan dan wawancara yaitu mengenai asal usul tradisi mappaoli bапиа, prosesi pelaksanaan, makna dan simbol yang tekandung dalam upacara mappaoli banua. Data sekunder berupa dokumen-dokumen resmi, misalnya jurnal, artikel, buku-buku, hasil penelitian yang berwujud laporan, dan sebagainya yang berhubungan langsung dengan substansi penelitian. Teknik analisis data yang digunakan dalam penelitian ini adalah analisis deskriptif kualitatif. Menurut Patton (dalam Moeleong, 2001: 208) analisis data merupakan proses mengatur urutan data, mengorganisasikan ke dalam suatu pola, kategori dan urutan suatu dasar. Adapun analisis data yang digunakan, antara lain: reduksi data, dan penyajian data (display data).

\section{HASIL DAN BAHASAN \\ 1. Asal Mula Tradisi Mappaoli Banua}

Keberadaan tradisi ritual mappaoli banua tidak lepas dari kilas balik sejarah Mosso sebagai kampung halaman raja pertama Kerajaan Balanipa. Kerajaan Balanipa menganut sistem kepemimpinan ala perahu, yaitu Anakodai Arajang, Banua Kaiyang to Lopo'. Artinya, yang menjadi nakhoda adalah raja tapi yang memiliki perahu adalah Banua Kaiyang, yang mana salah satunya adalah Mosso, yang sekarang ini sudah menjadi Desa Mosso. Masyarakat Banua Kaiyang Mosso adalah suku Mandar yang bermukim di Desa Mosso yang terletak di Kecamatan Balanipa, Kabupaten Polman, Provinsi Sulawesi Barat. Desa Mosso merupakan perkampungan tua yang berada di daerah pegunungan pada ketinggian 300 meter dari permukaan laut. Berdasarkan letak geografisnya, hampir semua perkampungan kuno di Sulawesi Barat terletak di daerah perbukitan. Demikian halnya dengan negeri-negeri pembentuk kerajaan Balanipa seperti Nepo dan Samasundu. Kerajaan Balanipa sebagai peletak dasar pembangunan kerajaan (landasan ideal dan landasan struktural), dan sebagai bapak ketua perserikatan seluruh kerajaan dalam wilayah Mandar yaitu pitu ulunna Salu dan Pitu Ba'bana Binanga (7 kerajaan yang berada di pegunungan dan 7 kerajaan yang berada di pesisir pantai). Kerajaan Balanipa mulai dikenal pada abad ke XV (tahun 1500) yang merupakan 4 federasi dari 4 kerajaan kecil yaitu Nepo, Samasundu, TodangTodang dan Mosso, selanjutnya ke-4 kerajaan kecil ini bergabung dalam persekutuan adat yang disebut Арре Вапиа Kaiyang. Masing-masing ke-4 negeri ini mempunyai kepala pemerintahan yang merupakan pemangku adat setempat (pappuangan) dan sebagai pucuk 
pimpinan ke-4 wilayah tersebut, dipilih dan diangkat seorang raja yang bergelar Mara'dia. (Sewang, 2010: 1).

Tradisi ritual mappaoli banua merupakan peninggalan leluhur Masyarakat Banua Kaiyang Mosso yaitu I Laso Mosso. I Laso Mosso adalah nenek moyang To Dilaling, raja pertama Kerajaan Balanipa. Masyarakat Mosso juga percaya bahwa I Laso Mosso sebagai manusia pertama yang tinggal di Banua Kaiyang Mosso, jauh sebelum Islam masuk dan adanya istilah arayang (raja) di Mandar. I Laso Mosso dimakamkan di atas bukit Buttu Tondoq, bukit yang paling tinggi letaknya dari segi geografi sekitar 500 meter dari permukaan laut. Dari sekian makam raja-raja atau tosalamaq di Kerajaan Pitu Baqbana Binanga semuanya terletak di atas bukit, akan tetapi makam I Laso Mossolah yang paling tinggi letaknya. Begitu tingginya, di atas puncak Buttu Tondoq kita bisa melihat makam raja-raja Balanipa yaitu I Manyambungi To Dilaling dan To Mepayung (raja kedua Balanipa), dan Maradiqdia Pallis (Maradia yang pertama masuk agama Islam) yang ketinggiannya sekitar 400 meter dari permukaan laut. Konon ketika akan wafat I Laso Mosso minta dimakamkan di atas bukit yang paling tinggi agar senantiasa dapat melihat keturunan-keturunannya yang bermukim di bawah bukit.
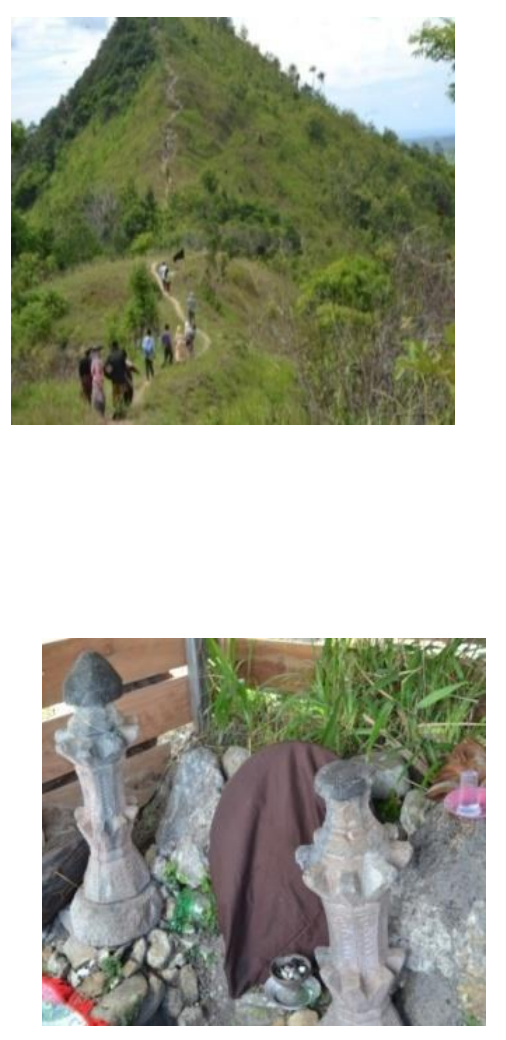

Gambar 1. Bukit Tondoq dan Makam I Laso Mosso

Sumber: Dalif

Secara harfiah mappaoli banua terdiri atas dua kata yaitu "mappaoli" terbentuk dari kata dasar "paoli" yang berarti obat dan mendapat awalan $m a$ (dalam Bahasa Indonesia $m a=$ awalan me) yang dimaknai sebagai kata kerja. Jadi mappaoli adalah kegiatan mengobati. Sedangkan pada kata "banua" diartikan sebagai kampung/ tanah kelahiran. Jadi tradisi ritual mappaoli banua merupakan salah satu kegiatan atau acara ritual mengobati kampung. Pengobatan di sini mempunyai makna multi tafsir, yang diarahkan pada penghormatan kepada alam, penyucian diri (manusia), doa bersama, dan yang paling utama adalah silaturahim atau ajang pertemuan antarkeluarga dan kerabat di makam I Laso Mosso.

Kegiatan mappaoli banua adalah kegiatan tahunan yang dilaksanakan oleh masyarakat Banua Kaiyang Mosso Balanipa. Sejak masa moyang mereka "I Laso Mosso" kegiatan ini telah dilaksanakan, hingga sampai generasi sekarang. Pelaksanaan kegiatan ini merupakan wujud dari kebersamaan dan persatuan masyarakat yang ada di Banua Kaiyang Mosso yaitu "Sumanga" ammesang" yang diartikan sebagai semangat persatuan. Dengan konsep tersebut, masyarakat Banua Kaiyang Mosso bahu membahu dan saling gotong royong melakuan ritual mappaoli banua mulai dari persiapan ritual sampai pada proses pelaksanaannya.

\section{Prosesi Pelaksanaan Ritual Mappaoli Banua}

Dalam pelaksanaannya ritual mappaoli banua terdiri atas beberapa tahap yaitu :

a. Tahap persiapan

Dalam pelaksanaan ritual mappaoli banua diperlukan persiapan yang matang, baik dari segi kesiapan dana maupun kesepakatan antara pemerintah setempat, 
tokoh adat dan masyarakat Mosso secara keseluruhan. Setelah kesepakatan dilakukan, maka dibentuklah susunan kepanitian yang akan mengurusi semua aspek-aspek kegiatan dalam pelaksanaan ritual mappaoli banua. Kepanitian yang terbentuk dibagi menjadi beberapa seksi yang bertanggungjawab sepenuhnya terhadap tugas yang dibebankan. Dalam pelaksanaan ritual mappaoli banua diperlukan dana yang cukup besar untuk membiayai seluruh keperluan upacara. Bagian yang bertugas mengumpulkan dana, mendatangi penduduk, tokoh adat, tokoh masyarakat untuk meminta sumbangan. Biasanya masyarakat dengan sukarela memberikan sumbangan, baik yang bermukim di Desa Mosso maupun yang tinggal di perantauan. Setelah dana terkumpul, selanjutnya dilakukan musyawarah untuk menentukan hari pelaksanaan. Semua tokoh adat misalnya maradia balanipa, pappuangan, ananguru, sando dan pemerintah setempat dimintai pendapat untuk menentukan hari pelaksanaan ritual mappaoli banua.

Setelah ada kesepakatan hari pelaksanaan maka panitia memesan kerbau (tedzong dalam bahasa Mandar), yang akan digunakan dalam ritual tersebut. Pemesanan kerbau dilakukan di daerah khusus yaitu di Tandung (nama salah satu desa di Kecamatan Tinambung yang dikenal dengan tempat pemeliharaan kerbau). Satu hari sebelum kegiatan upacara/ ritual dimulai, kerbau tersebut sudah dihadirkan di lokasi yang telah ditentukan. Persiapan selanjutnya adalah pembuatan anjat, yaitu wadah yang terbuat dari potongan bambu kuning dan rotan yang dirangkai menyerupai rumahrumahan, serta diberi penutup berbentuk kubah dengan tiang penyangga di keempat sudutnya. Fungsi anjat adalah tempat penyimpanan atau meletakkan sesajen yang berisi makanan tradisional dan buahbuahan, serta hasil bumi lainnya. Anjat harus selesai dibuat tiga hari sebelum hari pelaksanaan, anjat biasanya dibuat dua buah, satu ditempatkan di lokasi pelaksanaan yaitu di area pemotongan kerbau, dan satu lagi ditempatkan di lokasi makam leluhur di Bukit Tondoq.

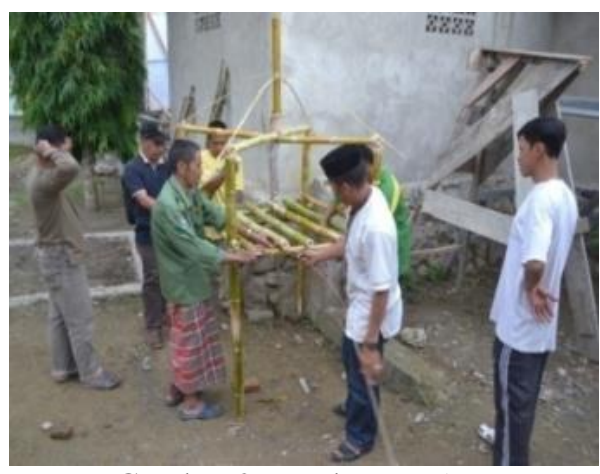

Gambar 2. Pembuatan Anjat Sumber: Dalif

b. Tahap Mapparawung Sossorang

Hari pertama prosesi mappaoli banua, dilakukan ritual mapparawung sossorang (menurunkan benda pusaka). Beberapa benda pusaka Banua Kaiyang Mosso tersimpan di rumah-rumah penduduk yang tergabung dalam kelompok pappuangan. Mereka dipercaya dapat menyimpan benda-benda pusaka itu dengan baik, karena masih memiliki hubungan kekerabatan dengan Raja Balanipa. Menurut penuturan kepala Desa Mosso, ketika terjadi peperangan melawan Belanda, benda-benda kerajaan ini disembunyikan oleh penduduk, sehingga keberadaan benda pusaka itu berada di tangan orang-orang yang sempat menyelamatkannya, dan sampai sekarang mereka menyimpan benda pusaka itu di rumahnya (wawancara dengan Supri, 10 Pebruari 2015).

Sossorang tersebut merupakan peninggalan leluhur, berupa gong yang bernama taqbilohe, dua buah gendang, perangkat kostum, dan benda-benda ritual peninggalan sando pertama. Penurunan benda pusaka itu dilakukan dengan upacara adat, di mana para pemangku adat dengan berpakaian adat Mandar (pasangan) mendatangi rumah di mana benda pusaka itu tersimpan. Sebelum penurunan sossorang terlebih dahulu dilakukan ritual pembacaan doa dipimpin 
oleh sando banua (dukun kampung) dan dilengkapi dengan sesajian berupa ketupat, burasa, sokkol, ayam bakaka (ayam yang dipanggang secara utuh). Selanjutnya iring-iringan yang terdiri atas para pemangku adat diramaikan dengan tabuhan gendang menuju ke tempat benda pusaka itu berada. Setelah benda pusaka itu diturunkan, lalu dibawa ke tempat pelaksanaan upacara (baruga). Sebagai penghormatan, selama benda pusaka itu dipajang di baruga, pada malam harinya diadakan pentas seni budaya. Berbagai sanggar seni budaya di Mandar diundang untuk ikut serta berpartisipasi dalam pelaksanaan tradisi mappaoli banua.

Pagelaran seni budaya menampilkan berbagai kesenian, misalnya seni tari, musik tradisional, vocal grup, dan drama tradisional masyarakat Banua Kaiyang Mosso. Pagelaran seni ini bertujuan untuk melestarikan seni budaya lokal.
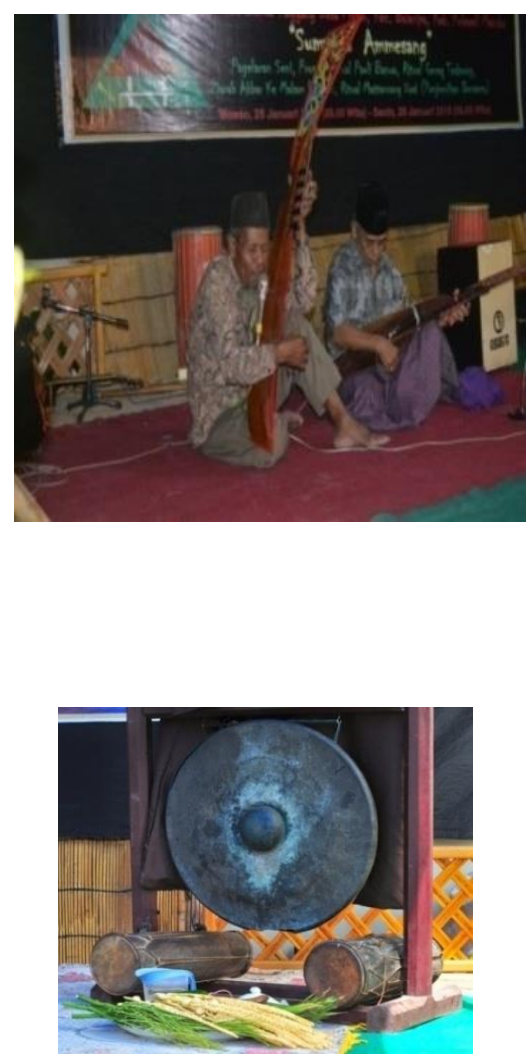

Gambar 3. Atraksi seni tradisional dan gong pusaka taqbilohe, gendang.
Sumber: Dalif

\section{c. Pangngereang Tedzong dan Mamminnai Tedzong}

Hari kedua dilakukan pangngereang tedzong (penyembelihan kerbau), ritual tersebut dilaksanakan di lokasi "assimemang" (lokasi yang telah ditentukan). Proses ritual penyembelihan kerbau diawali dengan pembakaran dupa oleh sando banua (dukun kampung). Penyembelihan kerbau dihadiri seluruh pemangku adat dan disaksikan langsung masyarakat pendukung kepercayaan tersebut. Sebelum penyembelihan kerbau dilakukan ritual mamminnai tedzong, yaitu pemberian minyak pada kepala kerbau. Pemberian minyak dilakukan oleh 24 pemangku adat dari ketiga rumpun yaitu Pappuangan Bulewanan, Pappuangan Saleppa dan Pappuangan Lemo masingmasing dengan perangkat adatnya. Berdasarkan stratifikasi sosial masyarakat Mandar, pappuangan adalah golongan tau piya, yaitu golongan ini menempati lapisan kedua sesudah todiang laiyana (keturunan raja). Mereka yang termasuk dalam golongan ini menempati kedudukan sebagai Paqbicara, Pappuangang, dan Pukkali atau Puang Kali (kadhi). Kedudukan Paqbicara, Pappuangang dan Pukkali adalah sebagai menteri-menteri kerajaan (Yahya, 2013: 65).

Para pemangku adat ini secara bergantian memberi minyak pada kepala kerbau yang telah diramu oleh sando dan diberi mantera. Caranya dengan mencelupkan tangan ke minyak lalu mengusap kepala kerbau dari bawah ke atas. Kerbau nampak dengan tenang dan menurut ketika diolesi minyak. Menurut penuturan sando banua, ada kesakralan ketika pemberian minyak pada kepala kerbau. Apabila yang mengolesi minyak adalah pemangkut adat maka kerbau tersebut terlihat tenang dan menurut, akan tetapi apabila yang memberi minyak bukan dari kalangan pemangku adat maka kerbau tersebut akan meronta-ronta, sehingga ritual mamminnai tedzong tidak boleh dilakukan dari kalangan masyarakat biasa 
(Wawancara dengan Mustamin, 12 Pebruari 2015).

Setelah ritual mamminnai tedzong selesai, selanjutnya dilakukan penyembelihan kerbau yang dipimpin sando banua. Sebelum disembelih kerbau dibersihkan dengan air yang diramu dengan bunga kelapa, daun sirih, pinang, dan kulit kayu, ke dalam ember yang berisi air. Penyembelihan kerbau dimaksudkan sebagai penjernihan dan persembahan kepada penguasa alam, agar nantinya alam, manusia dan budaya saling bersinergi satu sama lain dan mendapat restu dari leluhur. Setelah kerbau disembelih kemudian dibersihkan dagingnya, dan diolah menjadi beraneka masakan, misalnya gulai, gorengan dan sate. Daging kerbau yang dijadikan sate dipotong persegi empat berukuran besar. Sebagian masakan kerbau dijadikan hidangan pada tamu undangan yang datang menghadiri ritual mappaoli banua, dan sebagian lagi digunakan sebagai sesajen santapan ketika berziarah ke makam leluhur pada keesokan harinya. Menurut keyakinan masyarakat Mosso dengan memakan daging kerbau yang disembelih pada ritual mappaoli banua, dapat menjadi obat yang menguatkan tubuh.

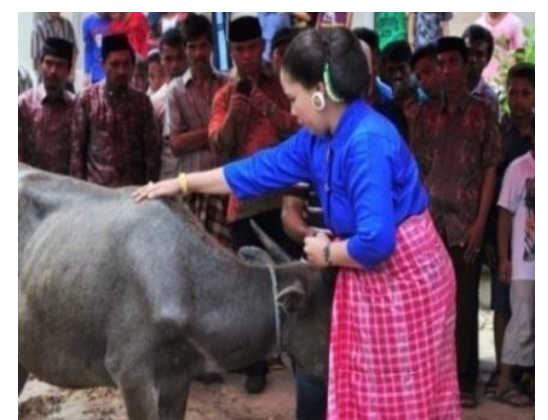

Gambar 4. Prosesi Mamminnai Tedzong Sumber: Ridwan

\section{d. Massamaya (Ziarah ke Makam Leluhur I Laso Mosso)}

Inti dari seluruh rangkaian upacara mappaoli banua adalah massamaya yaitu mengunjungi makam I Laso Mosso yang terletak di Bukit Tondoq (nama kampung kecil dalam Desa Mosso) pada hari ketiga.
Sebelum berangkat semua bekal berupa sesajen dan perangkat benda pusaka yang akan dibawa berziarah disiapkan, dan di letakkan di hamparan tikar di panggung upacara. Setelah para tamu undangan telah memenuhi tempat pelaksanaan ritual, maka acara pembukaan dimulai dengan pembacaan ayat suci al-Qur'an dan dilanjutkan dengan sambutan-sambutan masing-masing oleh ketua pelaksana, kepala Desa Mosso, dan Maradia Balanipa. Acara selanjutnya adalah mempersilakan seluruh anggota adat dari 24 pappungan naik ke atas panggung untuk pelaksanaan ritual yaitu baca-baca salama' yang dipimpin oleh sando to baine ( dukun perempuan) ibu dari sando banua.

\section{Gambar 5. Pembacaan Doa Sumber: Dalif}

Setelah doa bersama, dilanjutkan dengan pemukulan gong sebagai tanda acara inti yaitu ritual massamaya akan dilakukan. Pemukulan gong dipercayakan kepada Pappuangan Saleppa, sebagai

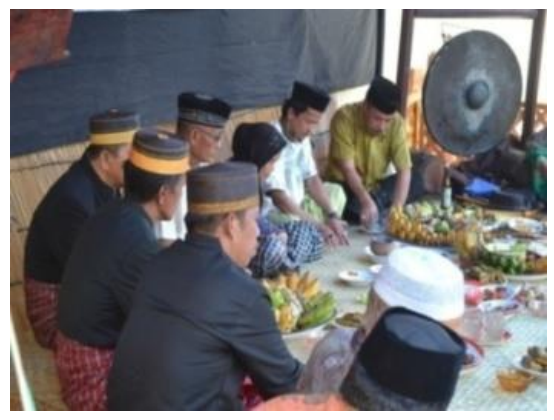

pappuangan tertua dalam Kerajaan Balanipa. Selanjutnya benda pusaka gong dan gendang ditabuh beramai-ramai. Dilanjutkan dengan pembacaan patroalla yaitu ikrar dan janji suci kepada leluhur oleh salah seorang pemangku adat. Sebelum berangkat menuju ke Bukit Tondoq ditampilkan atraksi pencak silat oleh sando banua dan perangkat adat dari masing-masing pappuangan. Setelah atraksi pencak silat selesai, maka berbondong-bondonglah masyarakat beserta pemangku adat menuju ke Bukit Tondoq untuk melakukan ziarah ke makam I Laso Mosso. Setiap rumpung keluarga 
membawa bekal makanan dan minuman sendiri, untuk dijadikan sesajen pada ritual pembacaan doa di makam I Laso Mosso.
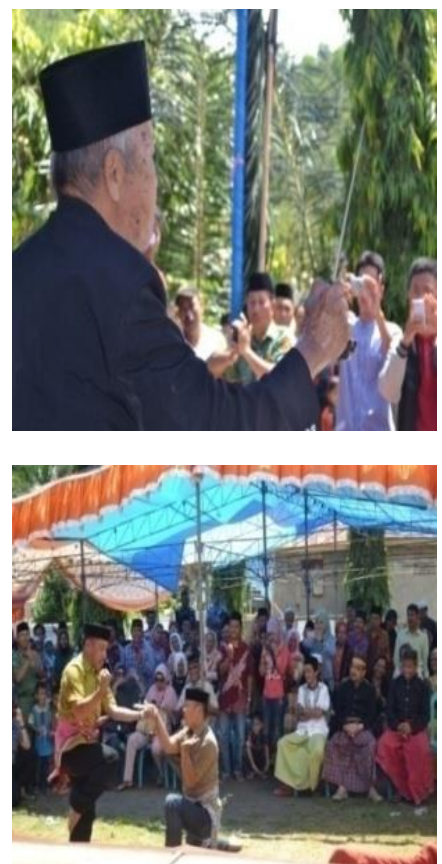

Gambar 6. Atraksi Patroalla dan Pencak Silat Sumber: Dalif.

Perjalanan menuju ke Bukit Tondoq, memerlukan tenaga untuk mendaki karena begitu tingginya, sehingga banyak warga yang lanjut usia kewalahan untuk mendaki Bukit Tondoq, namun hal tersebut tidak menyurutkan semangat mereka untuk berziarah. Setiba di puncak terlihat masyarakat berkumpul di makam I Laso Mosso, untuk pembacaan doa. Para pemangku adat dengan berpakaian pasangan memasuki area makam I Laso Mosso, yang menyerupai rumah. Di dekat makam digelar tikar untuk tempat pembacaan doa dan meletakkan berbagai macam sesajian. Kemudian sando banua duduk bersila di hadapan makam I Laso Mosso di samping pedupaan dan sesajen, begitu pedupaan mengepul sando mulai membaca doa yang ditujukan kepada arwah leluhur I Laso Mosso dan diikuti dengan hikmat para pemuka masyarakat dan pemangku adat.

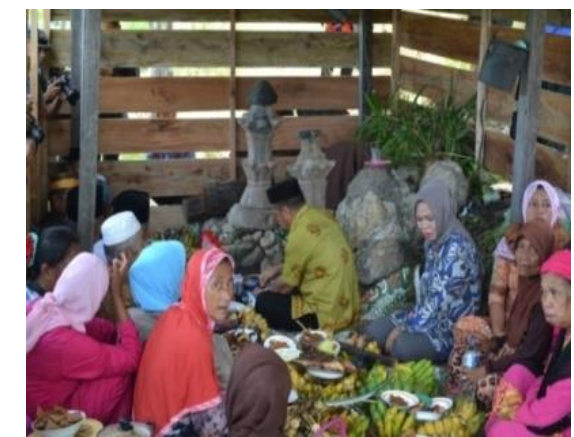

Gambar 7. Pembacaan doa di makam I Laso Mosso.

Sumber: Dalif.

Setelah pembacaan doa masingmasing rumpung keluarga mengambil sesajennya untuk dimakan bersama dengan keluarga mereka yang ikut serta dalam ziarah akbar tersebut. Menurut kepercayaan masyarakat Banua Kaiyang Mosso, sesajen dari berbagai macam makanan apabila telah didoakan di makam leluhur I Laso Mosso akan mendapat berkah, sehingga baik untuk dimakan bagi seluruh anggota keluarga. Setelah acara santap bersama, para peserta upacara melakukan siraman ke makam I Laso Mosso. Ketika prosesi penyiraman air, pada batu nisan di makam I Laso Mosso dilakukan oleh sando banua, masyarakat beramai-ramai mengambil air dengan cara menadahkan wadah pada tumpahan air yang disiramkan ke batu nisan. Air siraman tersebut dipercaya dapat dijadikan obat untuk menyembuhkan berbagai penyakit.

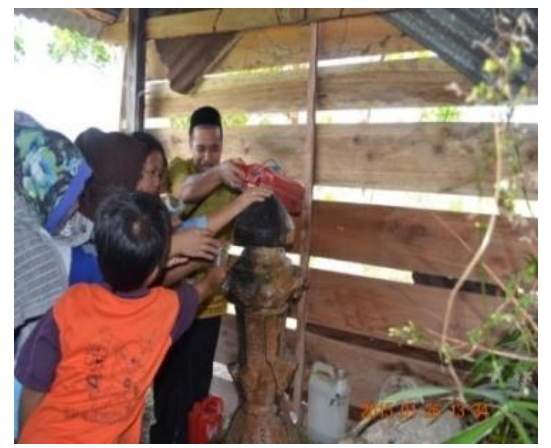

Gambar 8. Siraman di atas makam I Laso Mosso.

Sumber : Dalif 
Selain air siraman, masyarakat juga mengambil gundukan tanah di makam I Laso Mosso, untuk disimpan di kebun. Gundukan tanah itu dipercaya dapat menyuburkan tanaman dan penangkal dari hama penyakit. Kenyataan tersebut sejalan yang dikemukakan Geertz (1992: 33) bahwa dalam ritus terdapat sederetan suasana hati dan motivasi di suatu pihak yang dipertemukan dan membentuk kesadaran spiritual sebuah masyarakat. Dalam kehidupan masyarakat Mosso, ritual mappaoli banua merupakan perwujudan dari harapan dan motivasi serta memberi spirit pada masyarakat dalam menjalani kehidupannya.

\section{e. Mattannang Uwai}

Setelah kembali dari massamaya (ziarah akbar) dilakukan ritual mattannang uwai artinya memasang air, untuk digunakan merendam benda pusaka peninggalan sando pertama. Warga masyarakat berkumpul untuk melaksanakan ritual mattannang uwai, di rumah kepala Desa Mosso. Benda pusaka yang direndam berupa: (1) dua pisau yang digunakan sando pertama untuk memotong tali pusar bayi yang baru lahir, menurut mitos pisau tersebut datang secara gaib dan diberikan kepada sando pertama; (2) uang logam yang bertulisan Arab, menurut mitos uang logam tersebut keluar dari perut sando pertama; (3) gulungan kain bertulisan huruf Arab. Kesemua benda pusaka tersebut dimasukkan dalam ember berisi air dan diikatkan di tiang pusat rumah.

Prosesi pengobatan dilakukan oleh sando, dengan membacakan mantera sebelum air tersebut dimandikan atau disiramkan pada tubuh seseorang yang diobati. Sando mencelupkan rangkaian bunga kelapa, daun sirih, daun enau ke dalam rendaman air benda pusaka, kemudian dipukulkan ke tubuh orang yang akan diobati. Pengobatan dengan cara memukulkan rangkaian bunga kelapa ke tubuh pasien tidak terasa sakit apabila sando yang memukulkan, akan tetapi apabila orang lain yang memukulkan akan terasa sakit (wawancara dengan Mustamin 12 Pebruari 2015). Setelah pengobatan pasien, maka warga beramai-ramai mengambil sisa air untuk disimpan dan dijadikan obat.

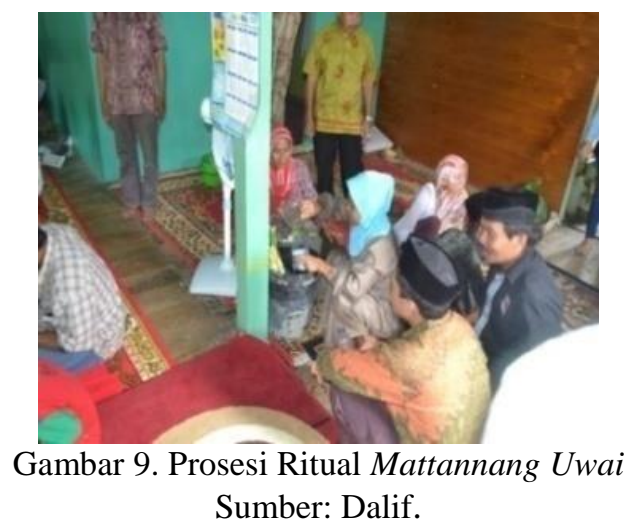

Tahapan terakhir dari upacara mappaoli banua adalah kunjungan ke laut, untuk memberi doa kepada keturunan yang berada di laut dengan membuat sesajen yang diletakkan ke dalam wadah yang berbentuk perahu. Sebelum sesajen di luncurkan ke laut, sando banua membacakan doa sebagai persembahan kepada dewa penguasa laut agar senantiasa menjaga masyarakat Banua Kaiyang Mosso dari bencana dan senantiasa dilimpahkan rezeki kepada masyarakat Banua Kaiyang Mosso. Ketika sesajen di luncurkan ke laut warga beramai-ramai untuk turun ke laut mengambil makanan dalam perahu. Mereka memercayai bahwa makanan tersebut dapat membawa berkah. Kegembiraan masyarakat Banua Kaiyang Mosso ditunjukkan dengan beramai-ramai mandi di laut, dengan harapan dapat membuang sial. Pelaksanaan ritual di laut merupakan penutup dari seluruh prosesi mappaoli banua yang diselenggarakan selama empat hari.

\section{Makna Simbolis dalam Tradisi Ritual Mappaoli Banua.}

Integritas manusia sepanjang hidupnya berkecimpung dalam simbol, simbol merupakan bagian integral dari hidup manusia. Pendapat Maram dalam 
(Pramono, 2009: 5) bahwa pengetahuan, kepercayaan, norma dan nilai-nilai tidak dapat eksis tanpa adanya simbol-simbol. Simbol memungkinkan manusia untuk menciptakan, mengkomunikasikan dan mengambil bagian serta mengalihkan komponen-komponen kebudayaan ke generasi berikutnya. Demikian halnya dalam tradisi mappaoli banua, berbagai rangkaian prosesi pelaksanaannya memiliki simbol-simbol yang memberi makna atau pesan kepada generasi keturunan dari leluhur mereka I Laso Mosso. Adapun makna dari simbol-simbol yang terkandung dalam pelaksanaan tradisi ritual mappaoli banua adalah sebagai berikut:

\section{a. Makna Simbolis dalam Interaksi Masyarakat. \\ Dalam proses interaksi sosial,} manusia mengkomunikasikan arti-arti kepada orang lain melalui simbol-simbol. Kemudian orang lain menginterpretasikan simbol-simbol itu dan mengarahkan tingkah laku mereka berdasarkan interpretasi mereka. Dengan kata lain, dalam interaksi sosial, aktor-aktor terlibat dalam proses saling memengaruhi (Meed dalam Datuan, 2011: 36). Dalam pelaksanaan ritual mappaoli banua, melibatkan hampir keseluruhan masyarakat Banua Kaiyang Mosso, pemuka adat dan pemerintah. Keikutsertaan orang-orang untuk memberi dukungan, baik moril maupun materil, dapat dimaknai sebagai kepedulian dan kecintaan kepada sang leluhur. Berkumpulnya seluruh pendukung kepercayaan ini merupakan ajang silaturahmi sebagai simbol persaudaraan dan kebersamaan serta keikhlasan untuk turut serta dalam pelaksanaan tradisi ritual mappaoli banua. Ada simbol kepedulian dan keikhlasan ketika masyarakat Banua Kaiyang Mosso menyumbangkan dana dan tenaga untuk pelaksanaan ritual. Tidak hanya masyarakat yang berdiam di Mosso, tetapi warga Mosso yang bertempat tinggal di daerah lain, turut serta memberi andil dalam pelaksanaan tradisi ritual tersebut. Ada simbol kegotongroyongan dan kerja sama ketika pembuatan baruga yaitu tempat pelaksanaan ritual dan pembuatan anjat. Simbol ini dimaknai dalam kehidupan bahwa pekerjaan berat akan terasa ringan, apabila dilakukan secara bersama-sama. Menurut Kades Mosso, bahwa masyarakat Mosso merasa bertanggungjawab sepenuhnya terhadap pelaksanaan ritual tersebut, tidak hanya menyerahkan sepenuhnya kepada panitia pelaksana, akan tetapi dimaknai sebagai bakti mereka kepada leluhurnya apabila mereka mengambil peran dalam pelaksanaan ritual tersebut (wawancara dengan Supri,10 Pebruari 2015).

$$
\text { Ketika dilakukan prosesi }
$$

mapparawung sossorang, masyarakat beserta pemangku adat berpartisipasi melakukan arak-arakan ke tempat pengambilan benda pusaka. Kegiatan ini dimaknai sebagai penghormatan warga Mosso terhadap benda kebesaran peninggalan leluhur. Berkumpulnya para pemangku adat maradia balanipa, ketiga pappuangan, pemerintah setempat dan sando, merupakan simbol dari sistem kekerabatan dan kedudukan para penguasa di Kerajaan Balanipa, yang mengandung makna sebagai kepatuhan para lembaga adat ini menjalankan perannya sebagaimana status kedudukan dalam masyarakat Banua Kaiyang Mosso.

\section{b. Makna Simbolis Peralatan Ritual 1) Anjat}

Anjat sebagai tempat sesajen adalah simbol penghormatan dan persembahan jamuan kepada leluhurnya. Anjat yang terbuat dari bambu kuning sebagai simbol emas, tumbuhnya harus menghadap ke matahari dan pemotongannya hanya dapat dilakukan oleh sando banua. Dimaknai bahwa apa yang dipersembahkan kepada leluhur haruslah yang terbaik dan memiliki derajat yang tinggi. Implementasi dari perilaku tersebut bahwa masyarakat Mosso sangat menghargai dan menjunjung tinggi norma-norma dan tata krama yang 
santun ketika mereka menjamu tamu. Simbol dari anjat dimaksudkan pula untuk mengundang kehadiran leluhur saat pemotongan kerbau dan pada saat ritual massamaya di makam I Laso Mosso.

\section{2) Sossorang (Benda Pusaka)}

Sossorang adalah benda pusaka warisan leluhur yang dianggap keramat dan sangat disakralkan. Merupakan simbol kebesaran leluhur yang selalu dihadirkan dalam prosesi ritual mappaoli banua. Makna dari kehadiran benda pusaka adalah menghadirkan roh leluhur untuk ikut serta dalam ritual karena menurut kepercayaan mereka bahwa benda pusaka itu memiliki kekuatan gaib. Menurut penuturan sando banua, bahwa kekuatan gaib yang ada pada benda pusaka tersebut dapat memberi isyarat jika akan terjadi sesuatu di Kampung Mosso, misalnya bencana alam, wabah penyakit atau kejadian luar biasa yang akan menimpa negeri. Tanda-tanda isyarat tersebut biasanya hanya dapat diketahui oleh sando melalui mimpi, atau benda pusaka itu akan bergetar dan mengeluarkan bunyi. Ketika isyarat itu datang maka merupakan pertanda atau peringatan dari leluhur, bahwa masyarakat Banua Kaiyang Mosso harus mengadakan ritual mappaoli banua, agar terhindar dari bencana alam atau wabah penyakit yang akan terjadi (wawancara dengan Mustamin, 12 Pebruari 2015).

Pada hari pelaksanaan ritual mappaoli banua benda pusaka berupa gong dan gendang dibunyikan sebagai simbol penanda akan dimulainya kegiatan ritual dan dimaknai sebagai pemanggil roh-roh leluhur untuk ikut serta dalam ritual. Masyarakat Banua Kaiyang Mosso meyakini bahwa benda pusaka (sossorang) tidak dapat dipisahkan dengan leluhur, di mana benda pusaka itu berada maka di sana pula ada roh leluhur. Bunyi-bunyian itu dimaknai pula sebagai sarana pengiring dan pelipur lara leluhur.

\section{c. Makna Simbolis Tedzong (Kerbau)}

Tedzong (kerbau) adalah salah satu unsur utama yang harus ada dalam ritual mappaoli banua. Tanpa kehadiran tedzong maka ritual tersebut tidak dapat dilaksanakan. Kerbau merupakan binatang yang disakralkan pada berbagai ritual di Sulawesi Selatan. Misalnya di Toraja, kerbau adalah hewan paling istimewa karena kerbau menjadi alat transaksi dalam perkawinan, dalam pewarisan, dan dalam pesta kematian. Kepemilikan kerbau menjadi salah satu simbol status sosial (https://msdatuan.wordpress.com/artikel/ke rbau-dalam-tradisi-masyarakat-Toraja/).

Demikian halnya pada masyarakat Mandar, kerbau adalah hewan yang disakralkan serta dihormati yang dimitoskan sebagai hewan tomanurung. Dengan demikian hewan ini menurut kepercayaan masyarakat bahari Mandar, binatang yang dilarang keras disebut ketika berada di laut karena dianggap pemali yang dapat mendatangkan bencana. Pengorbanan kerbau di Mandar bukan hanya dilakukan pada saat ritual mappaoli banua, akan tetapi pada upacara-upacara lain, misal pelantikan maradia diharuskan menanam kepala kerbau. Demikian halnya pada upacara perkawinan ketika pihak mempelai wanita meminta mensyaratkan kerbau sebagai sorong, berarti wanita tersebut adalah keturunan bangsawan (http://ridwanmandar.blogspot.com/2015/0 1/pengorbanan-kerbau-ritus-kunoyang.htm).

Menurut pemahaman masyarakat Banua Kaiyang Mosso bahwa, kerbau merupakan hewan persembahan yang memiliki kehormatan tertinggi dalam suatu ritual. Dalam ritual mappaoli banua, kerbau adalah simbol kesuburan, persatuan dan status sosial. Pada saat pemotongan kerbau masyarakat beramairamai mengambil darah kerbau untuk dijadikan sebagai obat dan digunakan pula sebagai penjaga kebun untuk pengusir hama tanaman. Begitu sakralnya pemahaman masyarakat Banua Kaiyang Mosso tentang hewan kerbau, sehingga bagian-bagian tertentu dari binatang 
tersebut dimaknai sebagai obat atau pembawa keberkahan.

\section{d. Makna dan Simbolis Mamminai Tedzong}

Ritual mamminai tedzong yaitu mengolesi kepala kerbau dengan minyak, merupakan simbol penjernihan dan pembersihan pada kerbau sebelum disembelih. Pengolesan minyak dilakukan dengan cara mengusap kepala kerbau dari bawah ke atas, adalah simbol kesuburan dan kelancaran dalam segala usaha yang dilakukan masyarakat Mosso dan simbol pengobatan untuk alam dan sekitarnya. Mamminnai tedzong dimaknai sebagai kegiatan yang dilakukan sebagai bentuk dari doa dan harapan masyarakat Banua Kaiyang Mosso akan kemakmuran dalam kehidupan mereka. Ada harapan bahwa tanam-tanaman akan tumbuh lebih subur, serta alam senantiasa bersahabat, jauh dari bencana alam dan hama yang akan mengganggu tanaman.

Begitu diagungkannya kerbau dalam ritual mamminnai tedzong, sehingga orangorang yang dapat mengolesi kepala kerbau hanyalah dari kalangan kelompok adat misalnya maradia, pappuangan, dan sando banua. Simbol ini memberi pesan bahwa keseluruhan dari lembaga adat harus bersatu dan rukun dalam menjaga negeri, baik yang ada di pegunungan (pitu babana binanga) maupun yang di daerah pantai (pitu ulunna salu), agar senantiasa menjalin silaturahmi dan mempererat persaudaraan.

\section{e. Makna dan Simbolis Sesajen}

Dalam ritual mappaoli banua berbagai sesajen yang dihadirkan sebagai kelengkapan ritual, ada berupa makanan, minuman dan peralatan upacara. Peralatan upacara berupa undung (dupa), indoleu (terbuat dari daun-daunan dan akar tumbuhan), makna dan simbol dupa yang dibakar untuk memanggil dan mendatangkan para roh leluhur untuk hadir dalam ritual tersebut. Bermacam-macam makanan yang disajikan masyarakat Mosso ketika melakukan ritual mappaoli banua misalnya: buras (nasi yang dibungkus daun pisang), atupe nabi (ketupat Nabi berbentuk segi tiga), sate daging yang diiris besar-besar, рири (ikan yang dihaluskan dibentuk segi tiga dan digoreng), tallo annas (telur asin), bau tappi (ikan asap), sokkol (nasi ketan), kue cucur, beberapa sisir loka raya (pisang raja), dan loka manurung. Kesemua sesajen itu di letakkan pada nampan yang berukuran besar yang disebut ande kappar. Hidangan tersebut merupakan satu kesatuan dari sesajen yang dihidangkan pada berbagai upacara ritual pada masyarakat Mandar. Sesajen ini merupakan simbol persembahan pada penguasa alam semesta dan persembahan kepada leluhur sebagai bentuk rasa syukur masyarakat Mosso.

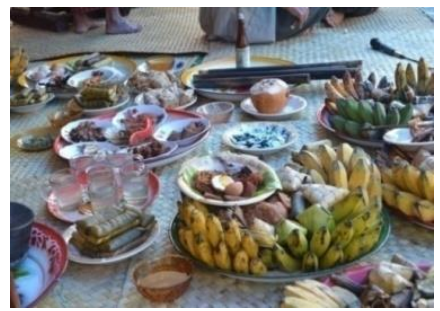

Gambar 10. Sesajen pada ritual mappaoli banua.

Sumber: Dalif 2015

Setelah pembacaan doa, semua makanan yang disajikan selain untuk persembahan kepada leluhur, juga dijadikan santapan jamuan kepada seluruh peserta upacara. Setiap rumpung keluarga di Mosso membuat sesajen untuk dipersembahkan kepada leluhur, dimaknai bahwa leluhur dapat menjadi wasilah untuk mengabulkan permohonan mereka. Doa yang berlafazkan Islam yang dibacakan pada ritual baca-baca salama adalah simbol keyakinan dan kepercayaan terhadap Tuhan Yang Maha Esa yang diyakini sebagai pencipta manusia dan seluruh alam semesta. Apabila masyarakat Mosso telah melakukan ritual mappaoli banua, biasanya kehidupan masyarakat Mosso dalam keadaan aman dan damai, serta hasil bumi akan tumbuh dengan subur (wawancara dengan Mustamin, 12 Pebruari 2015). 


\section{f. Makna dan Simbolis Atraksi Pencak Silat dan Pagelaran Seni Budaya}

Atraksi pencak silat yang dimainkan pada pelaksanaan ritual mappaoli banua merupakan permainan warisan leluhur masyarakat Mosso. Pencak silat adalah simbol keindahan gerak, keselarasan dari kreativitas seni yang dimainkan kaum pria, demikian pula sumpah setia kepada leluhur dari anak cucunya yang dipersembahkan lewat patroalla. Pagelaran seni yang dilaksanakan pada malam hari selama berlangsungnya ritual mappaoli banua, merupakan perwujudan dari kecintaan masyarakat Mosso akan seni budaya peninggalan leluhur, dan menjadi tugas mereka untuk menjaga kelestariannya agar dapat diwariskan ke generasi selanjutnya. Leluhur mereka telah menciptakan beragam seni budaya yang mempunyai cita rasa seni yang tinggi sebagai bagian dari perwujudan karakter dan jati diri masyarakat Banua Kaiyang Mosso.

\section{g. Makna dan Simbolis Ziarah ke Makam Leluhur}

Masyarakat Banua Kaiyang Mosso menganggap bahwa I Laso Mosso adalah nenek moyang orang Mosso, dan cikal bakal atau manusia pertama yang mendiami Banua Kaiyang Mosso, sehingga masyarakat Mosso senantiasa memuja dan mengkultuskan makamnya. Makna dan simbol ziarah akbar yang dilakukan masyarakat Mosso sebagai wujud kecintaan dan penghormatan mereka kepada sang leluhur. Di makam I Laso Mosso dilakukan ritual pembacaan doa untuk ketenangan arwah leluhur di alam baqa dan wujud bakti mereka kepada sang leluhur. Makna dan simbol siraman di makam I Laso Mosso adalah pensucian pada batu nisan untuk ketenangan arwahnya. Air siramannya digunakan untuk mengobati berbagai penyakit, penangkal dari segala mara bahaya dan ada juga yang menggunakan sebagai penyubur tanaman. Makan bersama setelah ritual dimaknai sebagai pernyataan rasa syukur akan rezeki dan karunia dari yang Kuasa yang disaksikan oleh roh leluhur I
Laso Mosso. Ziarah akbar ke makam I Laso Mosso, merupakan ajang silaturahmi antarwarga masyarakat bersama lembaga adat ketiga pappuangan dan maradia balanipa. Berziarah ke makam I Laso Mosso adalah simbol kecintaan masyarakat Mosso terhadap leluhurnya, yang diyakini dapat memotivasi mereka untuk senantiasa meningkatkan etos kerja dan menjaga persaudaraan sesama warga Banua Kaiyang Mosso.

\section{PENUTUP}

Eksistensi ritual mappaoli banua pada masyarakat Banua Kaiyang Mosso, merupakan media komunikasi masyarakat pendukung kepercayaan tersebut terhadap leluhurnya. Pelaksanaan ritual mappaoli bапиа dimaksudkan bahwa manusia dan alam harus senantiasa saling bersinergi, untuk mendapatkan keselamatan, ketentraman dan keberkahan bagi seluruh warga masyarakat serta wujud bakti terhadap leluhur mereka I Laso Mosso. Setiap tahapan pelaksanaan ritus kuno ini tetap mengacu pada tata cara yang diwariskan pendahulu mereka, dan berproses sesuai dinamika kehidupan masyarakat pendukungnya. Tradisi ritual mappaoli banua adalah cerminan dari karakter dan jati diri masyarakat Mosso yang dilandasi pada perilaku gotong royong dan jalinan persaudaraan yang terbangun dalam mempertahankan dan melestarikan budaya serta kesenian masyarakat Banua Kaiyang Mosso.

Tradisi mappaoli banua sarat dengan simbol yang memberi makna dalam kehidupan masyarakat Mosso. Pada ritual mamminai tedzong, sebagai simbol kesuburan dimaknai bahwa semua tanamtanaman yang tumbuh di bumi Banua Kaiyang Mosso akan tumbuh dengan subur, agar dapat mensejahterakan masyarakat. Benda pusaka (assosorang) sebagai simbol kebesaran dan kejayaan masa lampau, dan dipercayai sebagai tempat bersemayamnya roh-roh leluhur, dengan mensucikan benda pusaka peninggalan leluhur berarti menghormati 
dan memuja akan kebesarannya. Mattanang uwai adalah simbol dari kekuatan benda-benda pusaka dalam mengobati berbagai penyakit yang bermakna bukan hanya mengobati manusia, akan tetapi mengobati kampung/ negeri, agar terhindar dari berbagai wabah penyakit. Massamaya adalah ziarah akbar ke makam leluhur mereka I Laso Mosso, merupakan simbol kecintaan dan penghormatan kepada leluhur, dengan senantiasa mengunjungi dan memilihara makamnya. Ziarah akbar merupakan wujud persaudaraan dan ajang silaturahmi masyarakat Mosso baik yang bertempat tinggal di Mosso maupun yang datang dari perantauan. Tradisi mappaoli banua merupakan asset budaya masyarakat Banua Kaiyang Mosso Mandar yang tetap bertahan di tengah arus modernisasi dan dinamika perkembangan kebudayaan. Oleh karena itu perlu dukungan dari pemerintah setempat dan instansi terkait untuk tetap memberi peluang dan ruang bagi masyarakat pendukung kepercayaan tersebut dalam melestarikan kebudayaannya.

\section{DAFTAR SUMBER}

1. Jurnal, Makalah, Laporan Penelitian, Skripsi dan Tesis

Datuan, Maeke Yulita. 2011.

Makna Simbolik Tau-tau dalam Sistem Stratifikasi Sosial pada Pelaksanaan Upacara Rambu Solo Kabupaten Tana Toraja. Skripsi. Makassar: Fakultas Ilmu Sosial dan Ilmu Politik UNHAS.

Endahwati, Sri, dkk. 2012.

"Upacara Adat Jolenan di Kecamatan Kaligesing Kabupaten Purworejo: Kajian Makna Simbolik dan Nilai Religius" dalam. Basastra Vol. 1 No. 1 April 2012. Hlm 157-170.

Hamiruddin, Udu. 2012.

"Tradisi Kangkilo: Salah Satu Modal Sosial Budaya bagi Pembentukan Karakter Positif Masyarakat Buton", dalam Prosiding. Kendari: Universitas Haluoleo.

Ismail, Arifuddin. 2014.

"Unsur-Unsur Islam dalam Ritual Nelayan Mandar di Pambusuang Kabupaten Poliwali Mandar Provinsi Sulawesi Barat" dalam Walasuji Vol. 5 No. 2. Desember 2014. Hlm.277-287.

Jumiaty. 2013.

Makna Simbolik Tradisi To Ma'badong

dalam Upacara Rambu Solo di Kabupaten Tana Toraja. Skripsi. Makassar: Jurusan Komunikasi Fakultas Ilmu Sosial dan Ilmu Politik Universitas Hasanuddin.

Pramono, Ari Agung, 2009.

Makna Simbol Ritual Cembengan di Madukismo Kabupaten Bantul. Skripsi. Yogyakarta: Fakultas Ushuluddin Universitas Islam Sunan Kalijaga.

Saifullah, Andi. 2007.

Tradisi Sompa, Studi tentang Pandangan Masyarakat Wajo di Tengah Perubahan Sosial. Skripsi SHI. Malang: Universitas Islam Negeri Malang.

Soehadha, Muhammad. 2006.

"Teori Victor Turner, Aplikasi dan Implikasi Metodologisnya untuk Studi Agama-Agama" dalam Esensia Vol. 7 No. 2. Juni 2006. Hlm 207-212.

Yahya, Nurul Wardani.2013.

Strata Sosial Masyarakat Balanipa: Studi atas Ketatanegaraan Islam. Skripsi. Makassar: Fakultas Syariah dan Hukum UIN Alauddin.

\section{Buku}

Ansaar, 2010.

Nilai Budaya dalam Upacara Massossor Manurung di Kabupaten Maтuju. Makassar: Penerbit Dian Istana kerja sama dengan BPSNT Makassar.

Geertz, Clifford. 1992.

Kebudayaan dan Agama. (Terjemahan). Yogyakarta: Kanisus.

Hafid, Abdul. 2010. Penerapan Hukum Adat dalam Prosesi Baca-baa Nneneqta Adam di Lambanan Kabupaten Polman. Makassar: Dian 
Istana kerja sama dengan BPSNT

Makassar.

Koentjaraningrat. 1997.

Pengantar Antropologi (Pokok-Pokok

Etnografi II). Jakarta: PT Rineka Cipta.

Moeloeng, L.J. 2001.

Metodologi Penelitian Kualitatif.

Bandung: PT Remaja Rosdakarya.

Sewang, Anwar.2001.

Sosialisasi Siri pada Masyarakat

Mandar. Penerbit Yayasan Maha Putra

Mandar

\section{Sumber Internet}

http://ridwanmandar.blogspot.com/2015/0

1/pengorbanan-kerbau-ritus-kuno-

yang.html diakses tanggal 30 Maret 2015

https://msdatuan.wordpress.com/artikel/ker bau-dalam-tradisi-masyarakat-

toraja/diakses tanggal 27 Mei 2015.

\section{Informan}

Mustamin (54 tahun). 2015

Sando Banua. Wawancara. Balanipa, 12

Pebruari 2015.

Supri (45 tahun)2015

Kepala Desa Mosso. wawancara. Mosso, 10 Pebruari 2015 